\title{
Education in the digital economy: students' view
}

\author{
Bakeeva Larisa \\ Saint-Petersburg Mining University \\ Department of higher mathematics \\ Saint-Petersburg, Russian Federation \\ larisabakeeva@yandex.ru
}

\author{
Pastukhova Elena \\ Saint-Petersburg Mining University \\ Department of higher mathematics \\ Saint-Petersburg, Russian Federation \\ pastukhova.elena@mail.ru
}

\author{
Romanova Yulia \\ Saint-Petersburg Mining University \\ Department of higher mathematics \\ Saint-Petersburg, Russian Federation \\ ysr@bk.ru
}

\begin{abstract}
The implementation of the government program "Digital Economy of the Russian Federation" requires the transformation and change of many areas of society, including education, starting from school. The development of science and technology led to the accumulation of huge amounts of information in various subject areas, to the development of information technologies and the creation of information systems. All this led to a process of rapid increase in knowledge and experience, which actively influenced the organization of the process of their transfer. Digital methods of information coding and the possibility of its transmission using digital channels have created new spheres of human activity and society, new concepts of "digital technology" and "digital economy». The value of education, as an integral part of any economy, is great. In the digital economy, staff training should move to a new level. The article presents and analyzes data from a survey of first and second year students of the University of various degrees and faculties, reflecting their view on future changes in the education system related to the implementation of this government program and the possibilities for students and the University to interact in adapting to the conditions of the "digital economy». Some problems that limit the effective development of the education system and its adaptation to the conditions of the "digital economy" are considered. Possible changes in the content of academic disciplines are proposed (on the example of the academic discipline «Mathematics»).
\end{abstract}

Keywords - survey, education, distance education, digital economy, digitalization, digital literacy, digital technologies, staffing, information resources, information security

\section{INTRODUCTION}

Everything develops in a spiral. And in its development mankind passed several turns of the spiral, each of it is reflected in the specifics of the society development. Periodizations of the society development are numerous. The most suitable for our research is the periodization, that characterizes the development of the information society. The term «information» is translated from Latin as «information, clarification, presentation». At present, there are a lot of interpretations of the concept «information» and practically in each subject area there are some clarifications. Most types of professional human activity are related to the use of information resources and technical means for their production, transformation, accumulation and transfer. Such human activity is called informational, and society is called informational. Throughout the history of human development, four types of information revolutions can be highlighted: the invention of writing, the invention of typography (methods of accumulating information), the invention of electricity (telegraph, telephone and radio information communication), the invention of microprocessor technology and personal computers (production, processing and information sale). The last revolution gave impetus to human civilization for the transition to an information society and the emergence of a higher form of information - knowledges. Each time, from one turn of the development spiral of society to another, less and less time passes; each subsequent stage of development of society is shorter than the previous one (the law of accelerating development). At the same time, the amount of information increases, and special formats (digital codes) and digital technical means are used to process, store and transmit it. The production of an information product begins, the market of information services appears and developing $[1,2]$. The share of mental labor in all spheres of human activity is increasing and knowledge and intelligence become the product of production. Digital and information technologies are using to analyze production and resources, development, exchange of information, increase the effectiveness of the society development. The emerging system of economic, social and cultural relations based on the use of digital communication technologies is an economy of a new format - a digital economy where, along with physical processes and objects of the real world, parallel to them there is their virtual reality.

\section{LITERATURE REVIEW}

In society, in production and in business, there is a need for new-generation personnel who will be adapted to digital technologies and will have the necessary skills to successfully realize themselves in the digital economy. In [3, 4], various analytical data are presented on the development of the «digital economy» in different countries and on the digitalization of various spheres of human activity, including educational systems. But these processes in each country proceed in different ways. Russia, for example, already is in the period of digital technology. By the number of Internet users, it ranks 1st in Europe and 6th in the world. Over the past 3 years, smartphone users have doubled, now it is $60 \%$ of the population, and in the share of the «digital economy» in GDP, Russia is only 2-3 times lower than the leading countries: China, the United States and India [4]. The number of users of state and municipal services increases every year: for example, in 2018 the number of users of the public services portal increased by 21 million (up to 86 million), while the number of visits increased for more than $30 \%$ (to 582 million) in compison with the year 2017 .

One of the implementation direction of the government program «Digital Economy of the Russian Federation» is called «Personnel and Education». The goal of this direction is to create a system of basic educational programs that ensures digital literacy of the population; implementation of a lifelong education strategy; development of retraining, advanced training and involvement of government employees in the digital economy, teachers, specialists over 50, pensioners and the disabled; implementation of a motivation system for participation in the Russian digital economy. Undoubtedly, the «digitalization» of the 
educational sphere should become an important step towards to the realization of the set goal. This path is not easy, it has its own problems, eliminated with time. But the most important thing is: how should it change the content of education? How do the process of «digitalization» of the educational sphere imagine the participants of the process: pupils, students? How do they understand the essence of the processes aimed at the «digitalization» of education in particular, and the transition to a «digital economy» in general? What «digital» competencies $[5,6,7,8]$ should a university graduate have?

\section{RESULTS}

Before taking any action to update the content of the academic discipline (for example, «Mathematics») and change the organization of the educational process, we conducted a survey of first- and second-year students of various specialties and areas of training. It should be noted that the scope of the future professional activity of programs is only indirectly related to the components of the «digital economy». The survey involved 275 students of the following degrees:

09.03.02 - «Information systems and technologies»,

15.03.01 - «Mechanical engineering»,

15.03.02 - «Technological machines and equipment»,

21.03.01 - «Oil and gas industry»,

$27.03 .01-\langle$ Standardization and metrology»,

$38.03 .01-\langle$ Economics»,

21.05.02 - «Applied geology»,

$21.05 .04-\ll$ Mining»,

21.05.06 - «Oil and gas equipment and technologies»,

23.05.01 - «Land transport and technological means».

The questionnaire contained four open questions with fields for a detailed answer:

1. How do you understand the term «digital economy», what does it include?

2. What can change for you personally in connection with the transition of our society to a «digital economy»?

3 . Should there be any changes in the education system and how can the University help you in the process of adapting to the «digital economy»?

4. What changes can be expected in the labor market and in working conditions during the transition to a «digital economy»?

\section{DISCUSSION}

In order to our results of the survey and the conclusions we made below do not seem unreasonable, we consider it appropriate to cite several definitions of the concept of «digital economy», especially since it undergoes clarification in the process of program implementation and numerous discussions.

For the first time, the term «digital economy» electronic economy based on the transition of humankind in its economic activity from processing atoms to processing electronic bits, was formulated in 1995 by American computer scientist Nicholas Negroponte [9].

The Decree of the President of the Russian Federation of May 9, 2017 No. 203 «On the Strategy for the Information Society Development in the Russian Federation for 20172030» defines the term «digital economy» as an economic activity in which large volumes of data in digital form are a key factor of production, the use of the results of the analysis of which, in comparison with traditional forms of management, let significantly increase the efficiency of various types of production, technologies, equipment, storage, sale, delivery of goods and services.

In a speech at the St. Petersburg Economic Forum in June 2017, President of the Russian Federation V.V. Putin stressed that «the digital economy is not a separate industry. This is the basis that allows creating qualitatively new business, trade, logistics, production models, changes the format of education, health care, public administration, communications between people, and therefore sets a new paradigm for the development of the state, the economy and the whole society».

During a meeting of the Council on Strategic Development and Priority Projects in July 2017, President of the Russian Federation V.V. Putin noted: «I would like to repeat that the digital economy is not a separate industry, in fact it is a way of life, a new basis for the development of the system of government, economy, business, social sphere, the whole society. And, of course, the formation of the digital economy is a matter of national security and independence of Russia, the competitiveness of domestic companies, the country's position in the world arena for the long term, in fact for decades to come».

The World Bank defines a «digital economy» as a «system of economic, social and cultural relations based on the use of digital information and communication technologies».

The «Economist» Research Center and IBM believe that «a digital economy is an economy that can provide highquality ICT infrastructure and mobilize ICT opportunities for the benefit of consumers, business and the government».

Thus, in publications, discussions $[3,7,10,11]$ it is noted that there are two approaches to the term «digital economy». The «classic» approach claims that the digital economy is an economy based on digital technology; at the same time, it is more correct to characterize it exclusively as an area of electronic goods and services (telemedicine, distance learning, sales). An expanded look at this term defines «digital economy» as the production of economic benefits using digital technologies (digitizing data, their maintenance and distribution, electronic money, etc.).

Now we are going to consider the results of the students survey.

We would like to recall that the questionnaire contained four open questions.

The first part of the question «How do you understand the term «digital economy», what does it include?» the majority of respondents could not give a clear answer. However, an analysis of the answers of the second part of the question will allow us to conclude that the young people of eighteen and nineteen years old clearly represent the structure of the «digital economy». The responses were (sorted by frequency descending):

- online banking, e-money (93\%);

- online services $(78 \%)$;

- electronic queue $(52,5 \%)$;

- online workflow (38\%);

- e-business, in particular, modernization of production with innovative electronic devices $(22 \%)$;

- online analogues of goods and services (books, consultation) $(17 \%)$ 
- online organization of the educational process registration for the re-take on the University website (in particular, more as a wish, since it is not implemented at the University yet) $(1,5 \%)$.

To the second question «What can change for you personally in connection with the transition of our society to the « digital economy?» the majority (88\%) answered with general phrases. Perhaps this happened because some of the structural elements of the «digital economy» are somehow present in everyday life, and are self-evident. But nevertheless, among the remaining $12 \%$, there were thoughtful answers. There were (in decreasing order of frequency):

- change in financial relations (lack of intermediaries in carrying out banking operations, increasing the speed of transactions, using only non-cash payments, the inability to make untraceable and anonymous payments and transfers, tightening state control over citizens' expenses!) (97\%)

- convenience of receiving goods and services and online payments $(95 \%)$

- remote work $(95 \%)$;

- attracting new customers for business development $(95 \%)$;

- improvement of the quality of life (less time is spent on getting services, more time is left for rest) $(52 \%)$;

increasing the need for specialists related to computer technology, but at the same time reducing the need for others and increasing unemployment (39\%);

- increase digital literacy (new IT skills) $(7 \%)$;

- electronic document circulation, access to databases $(5 \%)$

- informational vulnerability (cyber attacks) $(5 \%)$

- reduction of corruption (3\%).

To the question «Should there be any changes in the education system and how can the University help you in the process of adapting to the «digital economy?» the majority of respondents answered that they could adapt themselves to the conditions of the digital economy. But there were those who needed in-depth knowledge of information technology, economics, legal aspects of the digital economy, and information security. Additional electronic possibilities in organizing the educational process were also in demand: an electronic record book, student card, study materials, a library.

Regarding question "What changes can be expected in the labor market and in working conditions during the transition to a « digital economy?» the least common answers were received. But the answers gave some anxiety, fear for the future. After all, in the years of graduation of our respondents there are the final stages of the transition to a «digital economy», and their first years of work and professional development that will be on this period. Young people were worried about the emergence of new professions and jobs in the field of IT, the increase in unemployment, and the competition of highly qualified personnel (79\%). It should be noted, that among the 275 respondents, only 23 students took a degree in that field 09.03.02 - «Information Systems and Technologies». The remaining 252 students are future professional personnel of the mineral resource complex. Among answer on the last question there were:

- adequacy recruiting (49\%);
- the real wage, financial transparency of income and expenses $(47 \%)$;

- online workflow, an ordered structure of the economy $(29 \%)$;

- increased requirements for computer skills $(23 \%)$;

- the possibility of losing information (information security) (19\%);

- remote work (the company in one city and the employee in another one) (7\%);

- opportunities for training and obtaining additional education remotely $(5 \%)$.

\section{CONCLUSION}

Processing and analysis of the survey results helped to made a conclusion and outline some tasks, the solution of which will allow to adapt the educational system, educational content and organization of the educational process to work in a «digital economy».

1. Currently, the education has a sufficient level of introduction of digital technologies in the educational process, but it does not bring the expected results. Not all participants of this process actively use them due to various circumstances: insufficient provision of necessary equipment, incompetence of teachers in the field of information technology, limited access to the Internet in the learning process, insufficient use of electronic libraries and electronic educational resources, ineffective mechanisms for transmitting information, training and decision making etc. You can find a detailed analysis at $[2,3,4,12]$.

To solve this problem, it is necessary to constantly inform all participants of the educational process, for example, providing free access to shared electronic information stores, including electronic textbooks. Students of St. Petersburg Mining University have access to many electronic libraries, which contain a huge amount of literary sources necessary for successful learning, although many students hardly use these resources. Even the list is big:

- European Digital Library Europeana;

- Consultant Plus: reference and search system;

-Information and Publishing Center for Geology and Subsoil Use of the Ministry of Natural Resources and Ecology of the Russian Federation- «GEOINFORMMARK LLC»;

- Information and Analytical Center «Mineral»;

- World Digital Library;

- Scientific electronic library «Scopus»;

- Science electronic library «ScienceDirect»;

- Science electronic library «eLIBRARY»;

- Portal «Gumanitarnoe obrazovanie»;

- Federal portal «Russian education»;

- Federal repository «United collection of digital educational resources»);

- Electronic library system of publishing center «Lan»;

- Electronic Library of the Russian State Library (RSL);

- Electronic library of coursebooks;

- Electronic library system «EBS YURAYT»;

- Electronic library system «National digital resource «Rukont»»».

- University electronic library.

2. Changes should not circumvent the content of academic disciplines. For example, the mathematical preparation of students is very multifaceted, changes can affect many of its components.. In the process of teaching 
mathematics, it is necessary to establish the relationship of educational material with the degree of students, to demonstrate the use of mathematical skills and sections in the future when studying other disciplines and in practical activities. In our opinion, in the transition to a «digital economy», it is necessary to implement sections into the program of the Mathematics discipline that introduce students, for example, with elements of information coding theory, graph theory (queuing theory, Markov chains), so that young people would have an idea of what is the core of «digital technology». Consequently, in the curricula it is necessary to increase the proportion of basic sciences, especially in Mathematics, since it is required by the transition to a digital economy. For the confidence of the employee in his or her demand in the future, it is desirable to prepare him or her for work in related fields. This contributes to obtaining additional qualifications. Taking into account, the accelerating penetration of mathematical methods and computer technologies in almost all spheres of human activity, it is probably necessary to develop training in programs for obtaining additional qualifications in mathematics and information and computer technologies, including the use of high-performance computing systems (supercomputers). Forms of additional education can be very different: short-term courses, lecture cycles, internships, retraining with the issuance of state documents, postgraduate education in magistracy, etc. The importance of mathematics, which is the theoretical basis of the digital economy, the prestige and necessity of mathematical education should be reflected in the media $[13,14,15]$.

3 . One of the actual directions of development and improvement of the organization of the educational process may be the transition from the standard way of getting education to e-learning $[16,17]$. This will increase the interest of young generation in the learning process. Elearning is the use of personal mobile devices in education. This innovation will allow to reorganize the educational process: timely transfer of organizational information, such as class schedules, information on fees for dormitories; providing access to educational resources, including textbooks, teaching aids, reference books, etc.; support of a single platform for communication between students and teachers; organization of webinars and trainings; providing the possibility of testing and other types of performance monitoring [18, 19]. E-learning is an individual tool for education, but at the same time involves networking, teamwork and the creation of new student communities. Its main advantage is mobility, that allows organizing the learning process without reference to time and place, improving the quality of communication between the participants of the learning process. The disadvantages of elearning are small screen sizes and technical characteristics of mobile devices; the cost of these devices; providing access to the Internet, information security; overcoming conceptual differences between classical and mobile learning [20]. The active use of mobile applications in the educational sphere will not only facilitate the learning process, but also arouse the necessary interest in learning from the current generation, which will become the basis for preparing future staff to work with information progress [17].

4. The law of acceleration of development works in the field of engineering and technology. Computer equipment, computer networks, information technologies are being developed. Over the past 20 years, the flow of information has increased in 120 times. This trend will continue, and every 20 months the amount of information will increase in proportion by 2 times. So you can suggest that in 100 years the quantity all kinds of data entering the human brain will increase in 1200 times. It will either explode or turn into a cyborg [21]. But this is only an assumption, and the reality is that the emergence of all sorts of electronic devices and computerized devices contributes to the revaluation of values, lifestyle and changes in cultural leisure. The reappraisal of values leads to the fact that university graduates are worried about the fact that they do not meet the requirements of employers, do not have the necessary skills that are necessary for effective interaction with modern economic and social elements. Therefore, by the time the transition to the «digital economy» program is completed, competency structures [5, 6] should be formed and many elements of the educational environment should be improved: access to education (100\% accessibility to information resources of the University, federal educational services), education monitoring, improving the efficiency and quality of management decisions), the training of faculty and students (compulsory development of information and communication technologies, the formation of a new student profile that meets the needs of the social and economic sphere of society. Such changes will bring the educational process to a new level and increase its quality for successful implementation in the conditions of the «digital economy». Education will become «smart» and continuous, computer programs and telecommunications will be actively used in the organization of the educational process, people will be mainly engaged in information processing, and machines will be engaged in the production of energy and material products [4]. Is it only possible in all spheres of human activity? To solve this problem, a rigorous scientific theory of information environments is needed, which establishes the actual laws of the flow of energy-information processes during information interactions [2].

\section{REFERENCES}

[1]. Mikeshin, M.I. Innovational communities // Notes of the Mining Institute. 2010. Vol.187. P. 194-197.

[2]. Zotova, T.C. The development of smart education in the digital economy of Russia/ Zotova T.C., Miroshnicenco M.A./: Knowledge economy: innovation ecosystem and new industrialization of the region; Materials of the III All-Russian Scientific Conference on Innovation /Krasnodar. 2018. P. 79-85.

[3]. Amirov R.A. Digital economy and current tasks of its staffing in Russia / Amirov RA, Egorov E.V. // Management consulting. 2018. Vol. 9 (117). P. 42-50.

[4]. Evdokimov, K.V. Development of the system of additional education in the digital economy of Russia / Evdokimov, K.V., Samorukov V.I., Lyulin AB // Scientific support of the development of the agro-industrial complex in the conditions of import substitution. Collection of scientific papers. St. Petersburg, 2018. P. 310-313.

[5]. Makuseva, T.G. General cultural component as a way to form engineering competencies // International Conference on Interactive Collaborative Learning (ICL) 2013. Kazan, Russian Federation; 25 - 27 September 2013. P. 513-514.

[6]. Bagaeva, I., Iliashenko, O., Borremans, A. Theoretical and methodological aspects of the competence approach to the evaluation of the organization's personnel // MATEC Web of Conferences. Vol. 193. EDP Sciences, 2018/ . P. 237-242.

[7]. Ilin, I., Levina, A., \& Iliashenko, O. (2017). Enterprise architecture approach to mining companies engineering. Paper presented at the MATEC Web of Conferences, 106, Article number 08066. 
[8]. Alekseeva I.A. Efficiency of human capital management on the example of technical universities of St. Petersburg / I.A.Alekseeva, M.G.Gildingersh // Notes of the Mining Institute. 2018. Vol. 232. P. 421-427.

[9]. Negroponte N. Being Digital. New York : Alfred A. Knopf. 1995.

[10]. Research report: UK The road to digital learning// https://www.birmingham.ac.uk/Documents/HEFI/FUJ-EducationReport-UK.pdf

[11]. Deloitte. Industry 4.0: Challenges and Solutions for the Digital Transformation and Use of Exponential Technologies. Zurich : Deloitte, 2015.

[12]. Digital economics: a brief statistical compendium / G. I. Abdrakhmanova, L. M. Gokhberg, A. V. Demianenko et al .; Nat researches University "Higher School of Economics". M.: HSE, 2018.

[13]. V. P. Prokopiev Mathematical education is a necessary condition for the development of the digital economy // Modern education: content, technology, quality. Vol. 1.2018. P. 53-55.

[14]. Tondeur, J., Van Braak, J., Ertmer, P., \& Ottenbreit-Leftwich, A Understanding the relationship between teachers' pedagogical beliefs and technology use in education: a systematic review of qualitative evidence. Educational Technology Research and Development. Vol. 65(3). 2017. P. 555-575.
[15]. Teaching and Learning-Toolkit // https:// Education end owment foundation.org.uk/public/files/Toolkit/complete/EEF-TeachingLearning-Toolkit-October-2018.pdf

[16]. Barr, B. A. \& Miller, S. F. Higher education: The online teaching and learning experience. (Report). 2013. Retrieved from http://search.proquest.com/docview/1413415711.

[17]. Daniel Newman Top 6 Digital Transformation Trends In Education// https://www.forbes.com/sites/danielnewman/2017/

[18]. 07/18/top-6-digital-transformation-trends-ineducation/\#51b956ee2a9a

[19]. Admiraal, W., Louws, M., Lockhorst, D., Paas, T., Buynsters, M. Cviko, A., Kester, L. Teachers in school-based technology innovations: A typology of their beliefs on teaching and technology. Computers and Education, Vol. 114. 2017. P. 57-68.

[20]. Tondeur, J., van Braak, J., Siddiq, F., \& Scherer, R. Time for a new approach to prepare future teachers for educational technology use: Its meaning and measurement. Computers \& Education. Vol. 94. 2016. P. 134-150.

[21]. Akhtar, S., Warburton, S., \& Xu, W. The use of an online learning and teaching system for monitoring computer aided design student participation and predicting student success. International Journal of Technology and Design Education. Vol. 27(2). 2017. P. 251-270.

[22]. Smith, K. Perceptions of Preservice Teachers about Adaptive Learning Programs in K-8 Mathematics Education. Contemporary Educational Technology. Vol. 9(2). 2016. P. 111-130. 